ISSN: 2162-3104 Print/ ISSN: 2166-3750 Online

Volume 6, Issue 1 (2016), pp. 308-313

(C) Journal of International Students

http://jistudents.org/

\title{
Do Nondomestic Undergraduates Choose a Major Field In Order to Maximize Grade Point Averages?
}

\author{
Matthew E. Bergman \\ University of California, San Diego (USA) \\ Barry Fass-Holmes \\ University of California, San Diego (USA)
}

\begin{abstract}
The authors investigated whether undergraduates attending an American West Coast public university who were not U.S. citizens (nondomestic) maximized their grade point averages (GPA) through their choice of major field. Multiple regression hierarchical linear modeling analyses showed that major field's effect size was small for these undergraduates' academic marks in mandatory English writing classes and their term GPAs in the five most recent academic years. Engineering and economics, but not science, were significant predictors of writing marks. Economics, but not engineering or science, was a significant predictor of GPAs.
\end{abstract}

Keywords: academic success, English writing, grade point average, international undergraduate, major field, nondomestic undergraduate, permanent resident

Undergraduates' choice of major is affected by a diversity of variables which have been organized into four categories: sources of information and influence, job characteristics, fit and interest in subject, and characteristics of the major/degree (Beggs, Bantham, \& Taylor, 2008). These variables' role in nondomestic (i.e., internationals, permanent residents, and/or undocumented students whose native language is not English) undergraduates' (NDU) choice of major at American higher education institutions has not been reported, to our knowledge. Data on international 
undergraduates' choice of fields of study appear in the Institute of International Education's (IIE) annual Open Doors report. In academic years (AY) 2012-13 and 2013-14 (the most recent ones available at the time of this writing), international undergraduates' top five fields of study are business and management, engineering, social sciences, mathematics and computer science, and fine and applied arts (IIE, 2013, 2014). These fields account for over $65 \%$ of the international undergraduates attending American higher education institutions.

A more recent publication on NDU choice of major field (Vaughn, Bergman, \& Fass-Holmes, 2015) reported that, at an American West Coast public university (hereafter referred to as "the University"), engineering (ENG) and science (SCI) majors comprised approximately half of the NDU enrolled in English intensive-writing classes in the fall term of academic years (AY) 2009-10 through 2013-14, inclusive. NDU whose major field was economics (ECON) comprised an additional 17-21\%. These students enrolled in the English writing classes to fulfill the University's graduation requirements (Vaughn et al., 2015).

Why have ENG and SCI been popular among the University's NDU? One hypothesis is that the above variables which affect domestic undergraduates also affect NDU (Beggs et al., 2008). However, an interesting alternative is that NDU, in order to maximize their GPAs, choose a major based (at least in part) upon its English writing proficiency dependence. This alternative would predict that NDU with English writing weaknesses (as evidenced by low academic marks in English writing classes) choose major fields (such as ENG and SCI) that ostensibly depend more upon mathematics than English writing proficiency. The present study tested this hypothesis.

The following two questions were addressed by analyzing data detailed in Vaughn et al. (2015). Does major field predict NDU academic marks in English writing classes? Does major field predict NDU term GPA?

\section{RESEARCH METHOD}

NDU demographic and academic achievement data for AY2009-10 through 2013-14 inclusive were extracted from the University's student information system using IRB-approved procedures (Vaughn et al., 2015). Demographic variables included department, major, and residency status (Table 1 in Vaughn et al., 2015). Outcome variables were academic marks in English writing classes (details in Vaughn et al., 2015) and term GPAs.

Multiple regression hierarchical linear modeling (MRHLM) was employed (using STATA 13 software; StataCorp, 2013) to determine whether major fields predict academic marks in the English writing classes 
and/or term GPAs (outcome variables). MRHLM analyses were performed (rather than standard HLM that regressed one variable on another) because they would 1) provide a more complete picture of variables' contributions to regression equations (Nathans, Oswald, \& Nimon, 2012), and 2) isolate major field's effect by controlling for variables (e.g., academic standing, class, home country, etc.) which previous research has shown could otherwise confound the present study's analyses (details in Vaughn et al., 2015).

To address the above two questions, all models in the present study were performed on the entire set of NDU in the sample (Table 1). The outcome variables were nested within student (a student could have up to 6 writing class marks and 3 term GPAs per AY). Writing class marks and term GPAs were level 1 (within students) outcomes and major field (the study's predictor variable of interest) was a level 2 (across students) categorically coded variable-ECON vs. all others (the University did not have an undergraduate Business major, hence ECON was included in its stead; Vaughn et al., 2015); ENG vs. all others; SCI vs. all others. Predictor variables which standard HLM previously found to be significant (Vaughn et al., 2015) potentially could be confounding and thus were controlled in the present study; they included academic standing, class, college writing program, home country, new/continuing status, and residency status (MRHLM results for these variables are available from the authors upon request).

An example model is shown below. The level 1 equation indicates that a student's mark in any particular term is a function of that individual's (level 2) predicted grade $\left(\beta_{0 \mathrm{j}}\right)$ and random error $\left(\mathrm{r}_{\mathrm{ij}}\right)$. The level 2 equation indicates that a student's predicted grade $\left(\beta_{0 \mathrm{j}}\right)$ is a function of the average mark $\left(\gamma_{00}\right)$, the student's major field $\left(\gamma_{01}\right)$, a series of a control variables $\left(\gamma_{02}\right)$, and random normal error $\left(\mu_{0 \mathrm{j}}\right)$.

Level 1: mark $=\beta_{0 \mathrm{j}}+\mathrm{r}_{\mathrm{ij}}$

Level 2: $\beta_{0 \mathrm{j}}=\gamma_{00}+\gamma_{01}$ (major field) $+\gamma_{02}$ (controls) $+\mu_{0 \mathrm{j}}$

\section{RESULTS}

Table 1 shows only the statistically significant $(\mathrm{p}<.05)$ MRHLM results for major fields (non-significant results are available from the authors upon request). The regression coefficient ( $\beta$; effect size) represents the difference between the average mark (or term GPA) for the indicated major field and the corresponding value for major fields other than ECON, ENG, or SCI; e.g., AY2013-14 ECON majors earned average English writing class marks that were 0.157 lower (and earned term GPAs that were 0.117 lower) than the corresponding value for counterparts whose major field was not ECON, 
ENG, or SCI (Table 1). This value corresponded to roughly half of the grade point difference between $\mathrm{C}$ - and $\mathrm{C}$ (and likewise for GPA).

Table 1: Statistically Significant Major Field Effects on English Intensive-Writing Classes' Marks and Term GPAs (MRHLM Analyses) English Writing Classes' Marks Term GPAs

$\begin{array}{lllllllllllll}\text { Predictor } & \boldsymbol{\beta} & \text { SE } \boldsymbol{\beta} & \boldsymbol{p} & \mathbf{r}^{2} & \mathbf{N} & \mathbf{n} & \boldsymbol{\beta} & \mathrm{SE} \boldsymbol{\beta} & \boldsymbol{p} & \mathbf{r}^{2} & \mathbf{N} & \mathbf{n}\end{array}$

2013-14 .23221734351 .49423124622

$\begin{array}{llll}\text { Economics } & -.157 & .049 & .001\end{array}$ $-.117 .033<.001$

$\begin{array}{lll}\text { Engineering } & -.108 \quad 045 \quad .017\end{array}$

2012-13

.22417033514

.49618103746

$\begin{array}{llll}\text { Economics } & -.163 & .053 & .002\end{array}$

$-.161 \quad .034<.001$

$\begin{array}{llll}\text { Engineering }-.139 & .048 \quad & .004\end{array}$

Science

$\begin{array}{lll}-.119 & .049 \quad .015\end{array}$

2011-12

.23513662526

$.495 \quad 14742714$

Economics

$\begin{array}{lll}-.086 & 0380.025\end{array}$

Engineering - -.133 $0.055 \quad .015$

2010-11

.20112542262

.45513012392

Engineering -.139 $0.056 \quad 013$

2009-10

.21711982331

.43712372441

$\begin{array}{llll}\text { Economics } & -.129 & .059 & .028\end{array}$

Engineering $-.188 \quad .053<.001$

Note. Abbreviations: GPA=grade point average; $\beta=$ regression coefficient (effect size); SE $\beta=$ standard error of the regression coefficient; $p=$ probability (significance level); $\mathrm{r}^{2}=$ the proportion of variance accounted for by the model; $\mathrm{N}=$ number of $\mathrm{NDU}$; $\mathrm{n}=$ number of observations; base major field is others besides economics, engineering, science, or undecided; controls include academic standing, class, college writing program, home country, new/continuing status, and visa type (details in Vaughn et al., 2015)

The MRHLM analyses (controlling for potentially confounding variables identified by Vaughn et al., 2015) showed that ENG and ECON, but not SCI, were significant predictors of English writing class marks (Table 1). For each of the 5 AYs, NDU whose major field was ENG earned significantly lower marks than counterparts in other major fields. For 3 AYs (excluding 2010-11 and 2011-12), NDU whose major field was ECON also earned significantly lower writing marks than NDU in other major fields. For only AY2012-13, NDU whose major field was SCI earned significantly 
lower writing marks. Major fields had small effect sizes ( $\beta$ values less than $0.2)$.

The MRHLM analyses (controlling for potentially confounding variables; Vaughn et al., 2015) additionally showed that ENG and SCI were not significant predictors of term GPAs (Table 1). Only ECON had significant effects on term GPAs. For 3 AYs (2011-12, 2012-13, and 201314), NDU whose major field was ECON earned significantly lower term GPAs than NDU in other major fields. ECON was the only major field with an effect size ( $\beta$ values less than 0.2 ).

\section{DISCUSSION AND CONCLUSIONS}

The present study's hypothesis was that NDU based their choice of major field (at least in part) upon its English writing proficiency dependence. This study showed that NDU whose major field was ENG had significantly worse English writing marks in all five AYs (Table 1). However, the significant difference had a small effect size and corresponded to about half of the grade point difference between C- and C (Table 1). Counterparts in SCI had significantly worse marks in only one AY. The present study additionally showed that ENG and SCI were not significant predictors of term GPAs, while ECON was for three of the five AYs. These results therefore provided only partial support for the above hypothesis and suggested that NDU chose major fields in which English writing weakness had limited negative impact on marks and GPAs.

An implicit assumption in this discussion is that ENG and/or SCI majors do depend upon mathematics (rather than English writing) proficiency. One of several generalizations at the University (Fass-Holmes \& Vaughn, 2014) is that NDU gravitate to ENG and SCI major fields because these undergraduates have English writing weaknesses which can be mitigated by majoring in ENG or SCI (Fass-Holmes \& Vaughn, 2015). Additional generalizations are that NDU collectively cheat, and that their GPAs reflect grade inflation or less stringent grading criteria than for domestic undergraduates. This assumption could be incorrect, however; additional research will be necessary to test it.

A notable limitation of the present study's findings is their generalizability to other American higher education institutions. Although generalizability is not determined in this study, these findings are indicative that major fields' ostensible dependence upon mathematics plays a limited role in the University's NDU choice of major field. Future studies using MRHLM analyses with other universities' NDU data to test the present study's hypothesis would address this limitation and also facilitate datadriven decision making about how best to support and promote NDU 
academic success.

\section{REFERENCES}

Fass-Holmes, B., \& Vaughn, A. A. (2014). Are international undergraduates struggling academically? Journal of International Students, 4(1), $60-73$.

Fass-Holmes, B. \& Vaughn, A. A. (2015). Evidence that international undergraduates can succeed academically despite struggling with English. Journal of International Students, 5(3), 228-243.

Beggs, J. M., Bantham, J. H., \& Taylor, S. (2008). Distinguishing the factors influencing college students' choice of major. College Student Journal, 42(2), 381-394.

Institute of International Education. (2013). Open Doors 2013: International students in the United States and study abroad by American students are at all-time high. Retrieved from http://iie.org/Who-WeAre/News-and-Events/Press-Center/Press-Releases/2013/2013-1111-Open-Doors-Data

Institute of International Education. (2014). Open Doors 2014: International students in the United States and study abroad by American students are at all-time high. Retrieved from http://iie.org/Who-WeAre/News-and-Events/Press-Center/Press-Releases/2014/2014-1117-Open-Doors-Data

Nathans, L. L., Oswald, F. L., \& Nimon, K. (2012). Interpreting multiple linear regression: A guidebook of variable importance. Practical Assessment, Research \& Evaluation, 17(9). Retrieved from http://pareonline.net/getvn.asp? $\mathrm{v}=17 \& \mathrm{n}=9$

StataCorp. (2013). Stata Statistical Software: Release 13. College Station, TX: StataCorp LP.

Vaughn, A. A., Bergman, M., \& Fass-Holmes, B. (2015). Nonresident undergraduates' performance in English writing classeshierarchical linear modeling analysis. Journal of International Students, 5(4), 319-333.

MATTHEW E. BERGMAN, is a doctoral candidate in the Department of Political Science. His research interests include comparative institutions, comparative politics, international relations, and student achievement. Email: mebergma@ucsd.edu

BARRY FASS-HOLMES, PhD, is the Analytical Studies Coordinator for the International Students \& Programs Office in the International Center at the University of California, San Diego. He studies international students' academic achievement. Email: bfholmes@ucsd.edu 